\title{
Review
}

\section{Industrial catalysis: Strategies to enhance selectivity}

\author{
Renyang Zheng a , Zhicheng Liu b, Yangdong Wang b, Zaiku Xie ${ }^{\mathrm{a}, \mathrm{b}, *}$ \\ a China Petroleum \& Chemical Corporation, Beijing 100728, China \\ b SINOPEC Shanghai Research Institute of Petrochemical Technology, Shanghai 201208, China
}

\section{A R T I C L E I N F}

\section{Article history:}

Received 25 December 2019

Accepted 30 December 2019

Published 5 July 2020

\section{Keywords:}

Industrial catalysis

Selectivity

Thermodynamic equilibrium

Adsorption

Desorption

\begin{abstract}
A B S T R A C T
Precise control of catalytic selectivity is a key concept of green chemistry, and also an important driving force for the sustainable development of catalytic industry. Selectivity not only determines the atomic economy of the catalytic process, but also affects the energy consumption of subsequent separation process. The objective of this review is to illustrate successful catalyst design strategies to enhance selectivity, by using several important catalytic cases of petroleum refining and petrochemicals. These industrial applications and cutting-edge research cases mainly use the strategies of coupling, decoupling or confinement of adsorption sites and active sites to tune the diffusion barrier and activation energy barrier in different routes, so as to improve the selectivity of catalyst. Based on the preliminary understanding of selectivity improvement, it is necessary to systematically investigate the selective catalytic processes using combination of multiple strategies, thereby realizing the design of highly selective catalyst over reasonable time scales and space scales.
\end{abstract}

(C) 2020, Dalian Institute of Chemical Physics, Chinese Academy of Sciences. Published by Elsevier B.V. All rights reserved.

\section{Introduction}

In the chemical industry, most processes (more than 80\%) involve catalysis especially in the petroleum refining and petrochemicals. As a core technology with great influence on socio-economic development [1], industrial catalysis accounts directly or indirectly for about $20 \%-30 \%$ of world gross domestic product (GDP) [2].

Precise control of catalytic selectivity, producing one molecule out of many other thermodynamically feasible product molecules, is a key green chemistry concept in developing clean processes [3-5]. Facing the dual challenges of resource and environment, catalytic selectivity has become an important driving force for sustainable development. A catalyst usually produces more than one product, and the preferred formation of the desired molecule is more important than the overall activity. It is known to all that developing active, selective and stable heterogeneous catalysts is vital to industrial development [6]. Among them, insufficient selectivity toward target product is a major difficulty $[7,8]$. There are conventional approaches to increase catalytic activity such as adjusting temperature and/or pressure, while to solve the catalytic stability by continuously regeneration of catalysts. However, selectivity directly determines the atomic economy of the catalytic process and also affects the energy consumption of subsequent separation process. There is a dilemma of selectivity limitation in catalysis saying "the more the activity, the less the selectivity".

Here, we emphasize the need to focus on the catalyst design strategies for selectivity, rather than activity, to overcome the thermodynamic equilibrium limited reactions. As shown in Fig. 1 , during an overall catalytic reaction, the reactants and products undergo a series of steps over the catalyst $[9,10]$, including:

\footnotetext{
* Corresponding author. E-mail: xzk@sinopec.com

This work was supported by the National Natural Science Foundation of China (91434102).

DOI: 10.1016/S1872-2067(20)63578-1 | http://www.sciencedirect.com/science/journal/18722067 | Chin. J. Catal., Vol. 41, No. 7, July 2020
} 


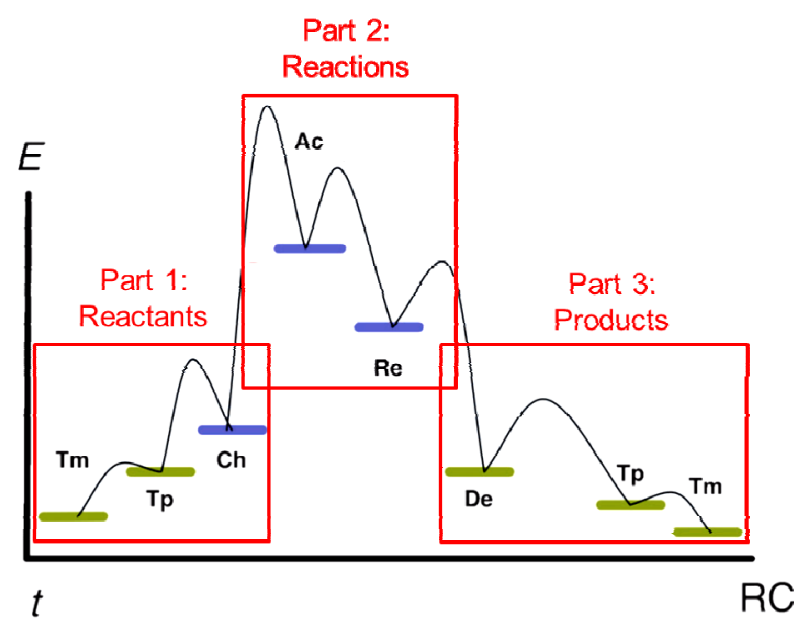

Fig. 1. Change in energy $(E)$ of a catalytic system with respect to the reaction coordinate (RC). Tm: macroscopic transport, Tp: transport in pores or solvation shells, Ch: chemisorption, AC: activation (dissociation), Re: reaction, De: desorption, dissociation. Adapted with permission from Ref. [10]. Copyright 2015 Wiley.

(1) Steps related to reactants: reactants' macroscopic transport, transport in pores or solvation shells, and chemisorption.

(2) Steps related to reactions: activation (dissociation), surface reaction and intermediate formation on active sites.

(3) Steps related to products: products' desorption, transport in pores or solvation shells, and macroscopic transport.

A previous literature has summarized the methods to overcome equilibrium limitation from catalyst to reaction engineering [11]. In this review, we focus on the catalysts design strategies to enhance selectivity in selected industrial catalysis cases, classified by the above three parts of catalytic steps. From the implications of gasoline desulfurization, styrene production, ethylbenzene deacetylation, and selective benzene hydrogenation, we explore the nature of improving selectivity in heterogeneous catalysis. We hope this review provide insight for industrial application of novel catalysts in the future.

\section{Catalytic cases}

This chapter seeks, from an industrial view, to provide brief examples of the design strategies for catalytic selectivity. Each case includes its application background, key scientific problems and strategies to improve selectivity.

\subsection{Cases using adsorption (diffusion) of reactants}

\section{Catalytic adsorption desulfurization of gasoline (S-Zorb process)}

The environmental regulations on exhaust emissions of gasoline-powered transportation vehicles are becoming more stringent, requiring the refining industry around the world to produce cleaner gasoline $[12,13]$. In the emission limitation of Euro V and China V, sulfur content in gasoline is required to be less than $10 \mathrm{ppm}$. However, it is difficult for conventional hydrodesulfurization (HDS) to reduce the sulfur of liquid fuels to a very low level for gasoline without loss of octane number [14]. Thus, new desulfurization strategies have been explored to meet the high demand for ultra-low sulfur gasoline [15].

S-Zorb is a kind of ultra-deep and high selective catalytic adsorption desulfurization process specially used for treating fluid catalytic cracking (FCC) gasoline [14-16]. The process is carried out over a fluidized-bed reactor and able to preserve octane number well while removing sulfur species effectively. The best performance has been observed for $\mathrm{Ni} / \mathrm{ZnO}$ system (Fig. 2) [12]. ZnO functions as sulfur carrier to provide high sulfur capacity, while $\mathrm{Ni}$ is used as the active site of sulfur removal. First, hydrogenation of sulfur compounds (mercaptan, thiophene and benzothiophene in gasoline) is occurred on metallic Ni to produce $\mathrm{H}_{2} \mathrm{~S}$. Then $\mathrm{H}_{2} \mathrm{~S}$ is absorbed by $\mathrm{ZnO}$ to form $\mathrm{ZnS}$, which recovers its activity through oxidation regeneration [12]. The synergistic effect of $\mathrm{ZnO}$ and $\mathrm{Ni}$ in close contact is the key scientific issue in this desulfurization process. On the one hand, it can convert $\mathrm{H}_{2} \mathrm{~S}$ rapidly, creating an extremely low $\mathrm{H}_{2} \mathrm{~S}$ partial pressure atmosphere, so as to avoid the side reactions such as $\mathrm{H}_{2} \mathrm{~S}$ combined with olefin (high octane number) to form mercaptan. On the other hand, it makes the metallic Ni and NiS in the reaction system always in a dynamic equilibrium, and sulfur species can transfer rapidly to $\mathrm{ZnO}$ in hydrogen atmosphere, which makes most of $\mathrm{Ni}$ remain in metallic state [17]. More importantly, in contrast to $\mathrm{NiS}$, the metallic Ni preferentially adsorbs thiophene rather than olefins and aromatics, leading to the outstanding performance of desulfurization and reducing octane loss simultaneously $[17,18]$. At present, to further solve the contradiction between reducing the olefin and increasing the octane number in the desulfurization process, it is necessary to optimize catalyst structures to promote the isomerization of olefins and alkanes in S-Zorb process [19].

\section{Side-chain alkylation of toluene with methanol}

Styrene is an important monomer used for the production of plastics and synthetic rubbers. In terms of monomer production rate, styrene ranks fourth in the global behind ethylene, vinyl chloride and propylene. However, conventional styrene production consumes tremendous amounts of energy, up to 10 times as much as the average level of monomers [20]. The

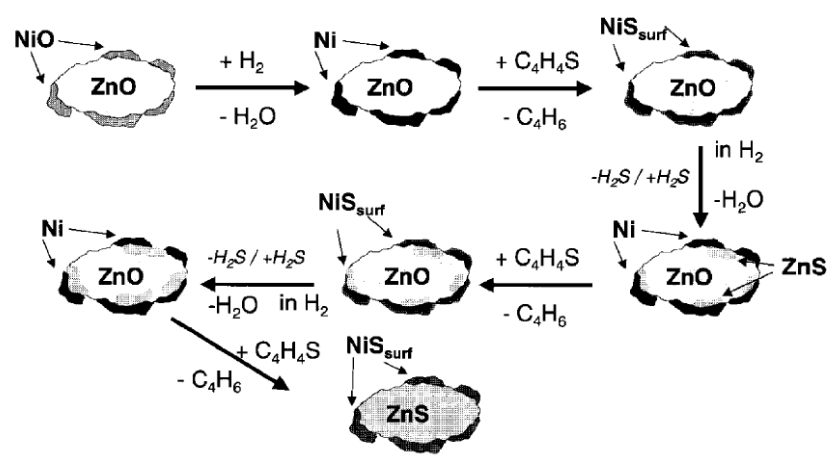

Fig. 2. Mechanism of catalytic adsorption desulfurization process. Reprinted with permission from Ref. [12]. Copyright 2003 Elsevier. 
conventional process requires two steps, including the benzene alkylation with ethylene to produce ethylbenzene, and then the catalytic dehydrogenation of ethylbenzene to produce styrene. Thus, side-chain alkylation of toluene with methanol, coupling the alkylation and dehydrogenation, is a potential technology to realize the one-step production of styrene under mild conditions [21].

It is widely accepted that an optimal synergy between acid and base sites is required for the efficient side-chain alkylation of toluene with methanol. Alkali-modified zeolite, especially cesium-modified zeolite $\mathrm{X}$ or $\mathrm{Y}$, has been recognized as a suitable catalyst for this reaction [22,23]. Generally, the role of acid sites is to adsorb and stabilize toluene, while the activation of methyl in toluene and the dehydrogenation of methanol to formaldehyde occur on the base sites (Fig. 3(a)) [24]. The produced formaldehyde acts as the actual alkylating reagent [25]. During alkylation, a couple of side-reactions occur. First, formaldehyde can self-decompose into $\mathrm{CO}$ and $\mathrm{H}_{2}$ before its utilization in toluene alkylation. Second, styrene can be further hydrogenated to ethylbenzene via transfer hydrogenation. Third, the presence of acid sites can convert methanol into dimethyl ether and also produce xylenes via the ring alkylation of toluene [26]. Thus, to improve the selectivity of the coupling between formaldehyde and toluene, it is necessary to regulate the distances and properties of acid-base sites, so that formaldehyde intermediate is activated by acid site to be polarized, while toluene is activated by basic sites to form benzyl anion and proton [28]. Much work so far has focused on the selectivity enhancement strategy of using zeolite catalysts by their adjustable acid-base properties and specific spatial configurations of acid-base sites (Fig. 3(b)) [27,28].

Despite many studies in the past decades, industrial application of this technology has not been realized in the world due to lack of efficient side-chain alkylation catalysts. In the future, developing acid-base bifunctional catalysts, which are compatible with the adsorption of toluene and stabilization of formaldehyde intermediate, should play a critical role in the high selective activation of methyl in toluene, as well as in solving the problems of excessive methanol decomposition and low tolu- ene conversion.

\subsection{Cases using surface reaction}

\section{Ethylbenzene dealkylation in xylene isomerization}

The main purpose of xylene isomerization is to increase the production of para-xylene, and at the same time, ethylbenzene must be converted to prevent its accumulation in the xylene isomerization unit recycle loop, because the boiling point of ethylbenzene is close with that of xylene isomers $[29,30]$. Typically, ethylbenzene can be converted via isomerization process (isomerization of ethylbenzene to xylene isomers) or ethylbenzene dealkylation process (reaction of ethylbenzene with hydrogen to form benzene and ethane) [29]. Due to the limitation of thermodynamic equilibrium, ethylbenzene conversion by isomerization process can only reach about $30 \%$. Hence, the unit load of adsorption separation and isomerization is large, and xylene loss is significant. Differently, ethylbenzene dealkylation process is not controlled by thermodynamic equilibrium, so it can reach high conversion. Meanwhile, the unit load is greatly reduced because benzene can be fractionated rapidly.

Ethylbenzene dealkylation process utilizes a metal-acid bifunctional catalyst, that is, an acidic zeolite to crack ethylbenzene into ethylene plus benzene and a metal function to exhaustively saturate the olefin thus formed [31]. Generally, ZSM-5 and other mesoporous zeolites are used as acid catalysts, and it is critical to choose appropriate metal functions, which must effectively saturate olefins without hydrogenation of aromatics in the feed. Dual-bed xylene isomerization is a representative industrial technology using ethylbenzene dealkylation process [31]. In this process, two types of catalysts are loaded into top and bottom of the axial reactor, respectively. The top bed catalyst, presumably noble metal/ZSM-5 catalyst, is selective for ethylbenzene dealkylation and cracking of non-aromatics while minimizing xylene loss [32,33]. Meanwhile, the bottom bed catalyst isomerizes the xylenes to the extent that the amount of para-xylene in the isomerization product is approximately (a)

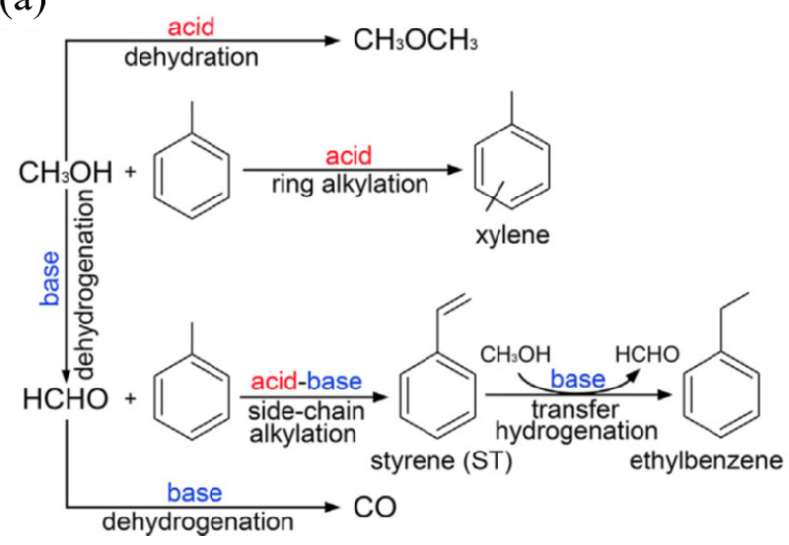

(b)

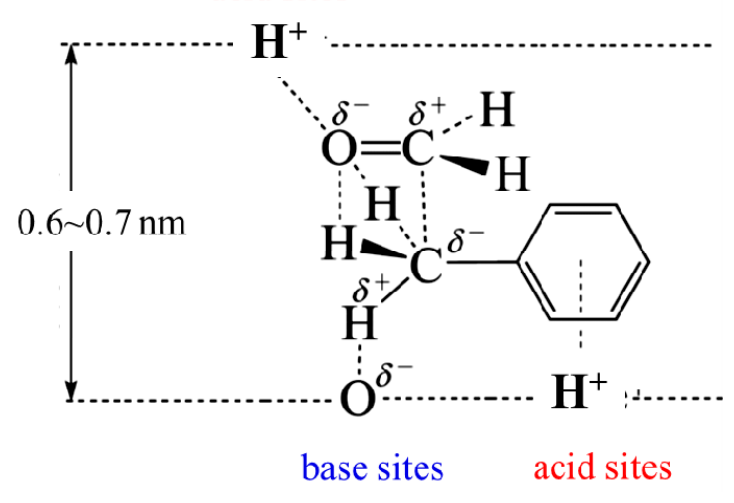

Fig. 3. (a) Various reaction pathways involved in toluene alkylation. Reprinted with permission from Ref. [24]. Copyright 2019 Elsevier. (b) Schematic diagram of side-chain alkylation of toluene catalyzed by acid-base sites. Adapted with permission from Ref. [27]. Copyright 1980 Elsevier. 
equal to that at the thermal equilibrium of the xylenes. The excellent catalytic performance is achieved by low xylene loss and high ethylbenzene conversion [34].

Besides, catalyst grading loading strategy by dual-bed or multi-bed is also applied in petroleum refining industry. Fix-bed residue hydrotreating process is another typical commercial example [35]. According to the requirements of various chemical reaction in residue hydrotreating, catalysts for hydrodemetallization (HDM), HDS and hydrodenitrification (HDN) are loaded in different stages in the reactor bed to optimize the selectivity and life of catalysts.

\subsection{Cases using desorption (diffusion) of products}

\section{Selective hydrogenation of benzene to cyclohexene}

Selective hydrogenation of benzene toward cyclohexene is an economically and environmentally significant reaction, since it provides an alternative synthetic route for nylon. Most of previous studies demonstrate that ruthenium-based catalysts are particularly suitable for the reaction $[36,37]$. One of the most important advances was the commercial application of $\mathrm{Ru}-\mathrm{Zn}$ Catalyst in selective hydrogenation of benzene that had high activity and excellent cyclohexene selectivity [38]. As cyclohexene is less stable than cyclohexane from the thermodynamics of the standard Gibbs free energy, the crucial point for improving the selectivity has to lie on the kinetics [39].

Hydrophilic modification of the Ru-based catalyst is one of the most effective ways to achieve improved cyclohexene selectivity. This has been confirmed by the observation that the cyclohexene yield is closely related to the hydrophilicity of support [40]. It was further proved by the fact that solubility of benzene in water is 6 times higher than that of cyclohexene. Thus, the stagnant water layer will give an enrichment of benzene on the catalyst surface, promoting desorption of cyclohexene from the catalyst by competitive adsorption. In addition, the diffusion gradient drives its migration into the aqueous phase, which can effectively prevent further hydrogenation of cyclohexene to cyclohexane, as depicted in the concentration profiles and mass fluxed for benzene and

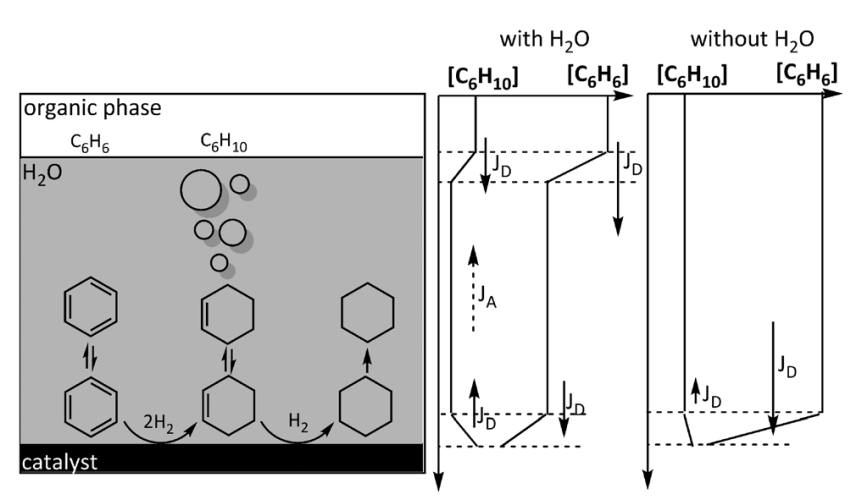

Fig. 4. Effect of the stagnant water layer on benzene hydrogenation. Straight arrows indicate diffusion transport (JD) and dashed arrows advective transport $\left(J_{A}\right)$. Adapted with permission from Ref. [39]. Copyright 1992 Elsevier. Reprinted with permission from Ref. [36]. Copyright 2015 Royal Society of Chemistry. cyclohexene in Fig. 4 [36,39]. Promoting the desorption of cyclohexene product from the catalyst surface by this hydrophilic modification is now an important guiding principle to improve the selectivity. Among plentiful modifications by the inorganic and organic additives, ionic liquid, and metal promoters [41,42], $\mathrm{ZnSO}_{4}$ is regarded as a most effective inorganic additive to the aqueous phase (stagnant water layer) for enhancing the selectivity. Recently, it is found that an insoluble zinc salt could be uniformly dispersed on the Ru surface and create a new interface between stagnant water layer and $\mathrm{Ru}$, which strengthens desorption of cyclohexene [43].

The strategy of the above case is characterized by using stagnant water layer to promote product desorption, while the more widely used strategy is to enhance the shape selectivity of products [44], which has also been successfully applied to aromatics industry. For example, para-xylene production by selective toluene disproportionation [44] or methylation of toluene with methanol $[26,45]$ is achieved by using shape-selective concept to greatly exceed equilibrium yield of preferred product through tuning rate of product diffusion.

\section{Strategy and nature of improving selectivity in heterogeneous catalysis}

Above cases of industrial application and frontier research inspire us to carefully analyze the catalyst design strategies (Table 1). This will help us to have a general and fundamental understanding of the rules on selectivity control in heterogeneous catalysis. In principle, three types of reaction sequences involved in selective catalysis should be considered: consecutive reaction, concurrent reaction, and consecutive-concurrent reaction. As shown in Fig. 5(a), A stands for the reactants, $\mathrm{B}$ for the desired products and $\mathrm{C}$ for the undesired products. Instead of a single potential-energy barrier that is reflected by the activation energy for a product formation, there are several potential-energy barriers with small energy differences in multipath reaction. Taking the concurrent reaction as an example, the corresponding potential-energy plot for the formation of two products is shown in Fig. 5(b) [46,47]. This relative heights of the activation barriers for different reactions determine the reaction selectivity. Small changes, such as $2 \mathrm{kcal} \mathrm{mol}^{-1}$, between potential-energy barriers completely change the product distribution [46]. These changes can be induced by tuning the catalyst structure, leading to the coupling, decoupling or confinement of adsorptive sites and active sites over different space scales and time scales.

In addition to fine control of individual catalytic steps, there is also a question may be asked on the limitation of thermodynamic equilibrium. By thermodynamic analysis, many selective catalytic reactions seem impossible to be commercialized, because the product selectivity in thermodynamic equilibrium cannot meet the industrial requirement. On the forecast of research and development outputs in the next one-two decades, European Cluster on Catalysis highlights a transient view of catalysis that accounts for out-of-equilibrium processes, instead of the current steady-state view [2]. Therefore, if we switch another 
Table 1

Summary of catalyst strategies classified by catalytic steps.

\begin{tabular}{|c|c|c|c|c|}
\hline Part & Case & Strategy & Effect & Ref. \\
\hline \multirow[t]{2}{*}{$\begin{array}{l}\text { 1. Adsorption (diffu- } \\
\text { sion) of reactants }\end{array}$} & $\begin{array}{l}\text { Catalytic adsorption desul- } \\
\text { furization of gasoline } \\
\text { (S-Zorb process) }\end{array}$ & Selective adsorption & $\begin{array}{c}\text { Metallic Ni preferentially adsorbs sulfur compound rather than } \\
\text { olefins and aromatics, resulting in the selective desulfurization } \\
\text { instead of olefin saturation. }\end{array}$ & {$[12,17]$} \\
\hline & $\begin{array}{l}\text { Side-chain alkylation of } \\
\text { toluene with methanol }\end{array}$ & $\begin{array}{l}\text { Specific spatial } \\
\text { adsorption }\end{array}$ & $\begin{array}{l}\text { Adsorption of toluene and stabilization of formaldehyde } \\
\text { intermediate occurs on appropriate acid-base sites. }\end{array}$ & {$[24]$} \\
\hline 2. Surface reaction & $\begin{array}{l}\text { Ethylbenzene dealkylation } \\
\text { in xylene isomerization }\end{array}$ & $\begin{array}{l}\text { Decoupling (separation) } \\
\text { of catalyst functions }\end{array}$ & $\begin{array}{l}\text { Dealkylation and isomerization are carried out in different } \\
\text { catalyst beds to increase the para-xylene production. }\end{array}$ & {$[31]$} \\
\hline $\begin{array}{l}\text { 3. Desorption (diffu- } \\
\text { sion) of products }\end{array}$ & $\begin{array}{c}\text { Selective hydrogenation of } \\
\text { benzene to cyclohexene }\end{array}$ & $\begin{array}{l}\text { Promoting product } \\
\text { desorption }\end{array}$ & $\begin{array}{c}\text { Products' transport in stagnant water layer is greatly } \\
\text { strengthen }\end{array}$ & {$[36,38]$} \\
\hline
\end{tabular}

(a) (1) consecutive reaction

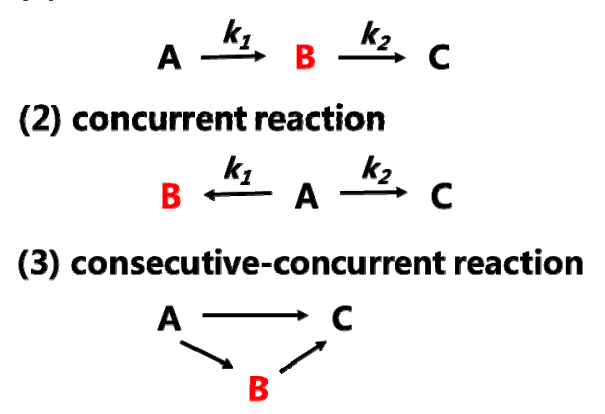

(b)

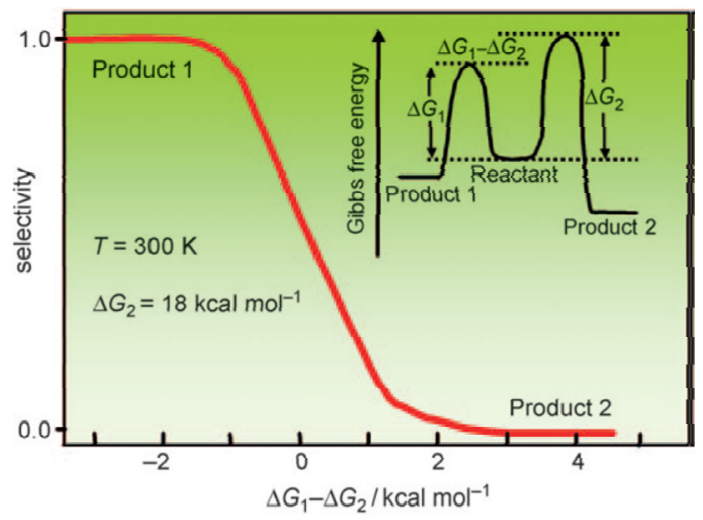

Fig. 5. (a) Scheme of multipath reaction classification; (b) potential-energy plot illustrating selectivity in heterogeneous catalysis of concurrent reaction. Adapted with permission from Ref. [46]. Copyright 2002 American Chemical Society. Reprinted with permission from Ref. [47]. Copyright 2008 Wiley.

perspective on the limitation problem of thermodynamic equilibrium, we can summarize the general strategies and propose the nature of selectivity improvement in heterogeneous catalysis, that is, maintaining the catalytic process at a specific out-of-equilibrium state through a limited space scale and time scale, thereby controlling product selectivity.

\section{Conclusions and outlook}

Improving selectivity is a vital direction for research and development of industrial catalysis. Catalyst design strategies, i.e., the coupling, decoupling (separation) or confinement of adsorptive sites and active sites, have played an important role in industrial applications and frontier research cases, such as gasoline adsorption desulfurization, side-chain alkylation of toluene, ethylbenzene deacetylation, and selective benzene hydrogenation. In complex reaction networks, the selectivity limitation can be solved by tuning the energy barrier toward different pathways. Moreover, it is necessary to pay more attention to catalytic chemistry in an out-of-equilibrium state and the method to control the reaction extent away from the thermodynamic equilibrium (selectivity). As we look ahead, it is important to use combination of strategies to rationally design catalyst structure over multiple space scales and time scales simultaneously, which is essentially a kind of mesoscale catalysis.

\section{References}

[1] Y. D. Wang, J. Shi, Z. H. Jin, Z. K. Xie, Chin. J. Catal., 2018, 39, 1147-1156.

[2] S. Perathoner, G. Centi, S. Gross, E. J. M. Hensen, European Cluster on Catalysis, 2016, 1-116.

[3] M. Y. He, Y. H. Sun, B. X. Han, Angew. Chem. Int. Ed., 2013, 52, 9620-9633.

[4] G. A. Somorjai, K. McCrea, Appl. Catal. A, 2001, 222, 3-18.

[5] J. H. Clark, Green Chem., 1999, 1, 1-8.

[6] C. M. Friend, B. Xu, Acc. Chem. Res., 2017, 50, 517-521.

[7] F. Cavani, G. Centi, C. Perego, A. Vaccari, Catal. Today, 2005, 99, $1-3$.

[8] Z. Wang, A. G. Zheng, R. Y. Zheng, M. F. Li, H. F. Li, G. T. Xu, G. F. Xia, RSC Adv., 2016, 6, 105063-105069.

[9] J. M. Thomas, W. J. Thomas, Principles and Practice of Heterogeneous Catalysis, 2nd ed., Wiley-VCH Verlag GmbH \& Co., Weinheim, 2015, 439-478.

[10] R. Schlogl, Angew. Chem. Int. Ed., 2015, 54, 3465-3520.

[11] J. N. Armor, Appl. Catal. A, 2001, 222, 91-99.

[12] I. V. Babich, J. A. Moulijn, Fuel, 2003, 82, 607-631.

[13] M. Li, H. Li, F. Jiang, Y. Chu, H. Nie, Catal. Today, 2010, 149, 35-39.

[14] S. Brunet, D. Mey, G. Perot, C. Bouchy, F. Diehl, Appl. Catal. A, 2005, 278, 143-172.

[15] Y. Zhang, Y. Yang, H. Han, M. Yang, L. Wang, Y. Zhang, Z. Jiang, C. Li, Appl. Catal. B, 2012, 119-120, 13-19.

[16] G. J. Greenwood, D. Kidd, L. Reed, in: National Petrochemical \& Refiners Association (NPRA) Annual Meeting, San Antonio, Texas, 


\title{
Graphical Abstract
}

Chin. J. Catal., 2020, 41: 1032-1038 doi: 10.1016/S1872-2067(20)63578-1

\section{Industrial catalysis: Strategies to enhance selectivity}

Renyang Zheng, Zhicheng Liu, Yangdong Wang, Zaiku Xie* China Petroleum \& Chemical Corporation; SINOPEC Shanghai Research Institute of Petrochemical Technology

Strategies to enhance selectivity of industrial catalysis cases such as petroleum refining and petrochemicals are summarized, in terms of adsorption of reactants, surface reaction, and desorption of products.

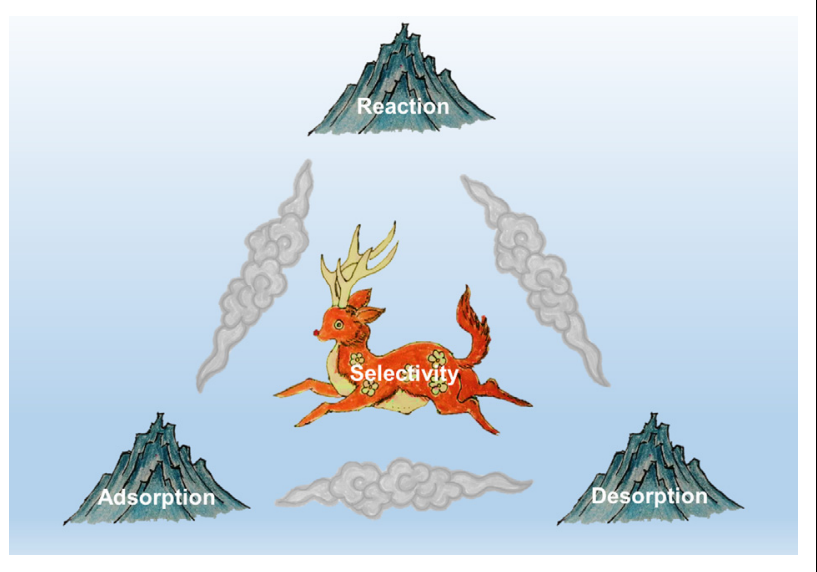

Weinheim, 2008, 3168-3194.

[32] D. L. Stern, US Patent 7247762, 2007.

[33] J. S. Abichandani, C. R. Venkat, US Patent 5516956, 1996.

[34] G. Mohr, in: AIChE Spring National Meeting, New Orleans, Louisiana, 2002, 123E.

[35] D. D. Li, Hydrotreating Process and Engineering, China Petrochemical Press, Beijing, 2004, 62-86.

[36] L. Foppa, J. Dupont, Chem. Soc. Rev., 2015, 44, 1886-1897.

[37] G. B. Zhou, R. F. Dou, H. Z. Bi, S. H. Xie, Y. Pei, K. N. Fan, M. H. Qiao, B. Sun, B. N. Zong, J. Catal., 2015, 332, 119-126.

[38] H. Nagahara, M. Ono, M. Konishi, Y. Fukuoka, Appl. Surf. Sci., 1997, $121 / 122,448-451$.

[39] J. Struijk, M. d'Angremond, W. J. M. Lucas-de-Regt, J. J. F. Scholten, Appl. Catal. A, 1992, 83, 263-295.

[40] H. J. Sun, W. Guo, X. L. Zhou, Z. H. Chen, Z. Y. Liu, S. C. Liu, Chin. J. Catal., 2011, 32, 1-16.

[41] Z. H. Chen, H. J. Sun, Z. K. Peng, J. Gao, B. J. Li, Z. Y. Liu, S. C. Liu, Ind. Eng. Chem. Res., 2019, 58, 13794-13803.

[42] L. Ronchin, L. Toniolo, Catal. Today, 2001, 66, 363-369.

[43] Z. K. Peng, X. Liu, H. N. Lin, Z. Wang, Z. J. Li, B. J. Li, Z. Y. Liu, S. C. Liu, J. Mater. Chem. A, 2016, 4, 17694-17703.

[44] T. F. Degnan, J. Catal., 2003, 216, 32-46.

[45] C. Wang, L. Zhang, X. Huang, Y. Zhu, G. Li, Q. Gu, J. Chen, L. Ma, X. Li, Q. He, J. Xu, Q. Sun, C. Song, M. Peng, J. Sun, D. Ma, Nat. Commun., 2019, 10, 4348.

[46] F. Zaera, J. Phys. Chem. B, 2002, 106, 4043-4052.

[47] G. A. Somorjai, J. Y. Park, Angew. Chem. Int. Ed., 2008, 47, 9212-9228. Schüth, J. Weitkamp, ed.) 2nd ed., Wiley-VCH Verlag GmbH \& Co.,

\section{工业催化：选择性提升策略}

\author{
郑仁垟 ${ }^{\mathrm{a}}$ ，刘志成 ${ }^{\mathrm{b}}$ ，王仰东 ${ }^{\mathrm{b}}$, 谢在库 ${ }^{\mathrm{a}, \mathrm{b},{ }^{*}}$ \\ ${ }^{\mathrm{a}}$ 中国石油化工股份有限公司，北京100728 \\ ${ }^{b}$ 中国石油化工股份有限公司上海石油化工研究院，上海201208
}

摘要: 工业催化直接或间接贡献了世界GDP的 $20 \%-30 \%$, 推动了产业变革和社会进步. 对于工业催化, 开发高活性、高选择 性和高稳定性的多相催化剂至关重要, 而选择性是最主要的挑战. 因为实现催化选择性的精确控制是绿色化学的重要概 
念之一, 更是工业催化可持续发展的重要驱动力; 而且, 选择性不仅决定了催化过程的原子经济性, 也影响到后续分离过 程的能耗. 针对多数工业催化反应存在 “活性越高、选择性越低” 的相互制约与矛盾问题, 本文以若干能源化工催化反应 为例, 试图总结催化选择性提升的一般策略, 以期为有关工业应用的催化新过程提供科学参考.

多相催化一般经历与反应物有关的步骤(反应物的外扩散、内扩散和化学吸附)、与反应有关的步骤(活化和表面反应)、 以及与产物相关的步骤(产物脱附、内扩散和外扩散). 本文依此归纳并举例说明提高选择性的一般策略. 在汽油催化吸附 脱硫中, 主要利用了催化剂中零价镍-氧化锌耦合活性中心的选择吸附策略, 使零价镍优先吸附含硫化合物, 从而实现选择 性脱硫而不饱和烯烃. 在甲苯和甲醇侧链烷基化反应中, 主要利用了特定空间分布的酸碱吸附位, 实现吸附甲苯和稳定甲 醛中间体的协同匹配. 在乙苯脱乙基型二甲苯异构化反应中, 主要利用了双床层对催化剂功能的分离策略, 在不同的择形 催化剂床层中分别进行乙苯脱乙基反应和二甲苯异构化反应, 从而提高对二甲苯的产量. 在苯选择加氢制环已烯反应中, 主要利用强化产品脱附的策略, 促进环已烯产品从亲水改性的催化剂表面脱附, 实现环已烯选择性的提升.

这些炼油与化工研究案例中同时存在多个连串-平行反应, 主要是利用吸附中心、反应中心在时间或空间上的耦合、 解耦或限域策略, 调控不同途径的扩散能垒、反应能垒, 实现了催化剂选择性的提升. 多相催化多是复杂过程, 基于提高选 择性的初步认识, 还要结合具体复杂催化过程, 系统研究单策略以及多策略组合作用下的选择催化过程, 实现在合理时间 尺度、空间尺度上设计高选择性的催化剂, 而这本质上是一种介尺度催化.

关键词: 工业催化; 选择性; 热力学平衡; 吸附; 脱附

收稿日期: 2019-12-25. 接受日期: 2019-12-30. 出版日期: 2020-07-05.

*通讯联系人. 电子信箱: xzk@sinopec.com

基金来源: 国家自然科学基金(91434102).

本文的电子版全文由Elsevier出版社在ScienceDirect上出版(http://www.sciencedirect.com/science/journal/18722067). 